\title{
Evaluation of digital text book vs. print text book learning perceptions among dental students during covid-19. A questionnaire study
}

\author{
Yasaswi ponukupati ${ }^{1}$, Swetha $\mathrm{P}^{2}$, Ravikanth $\mathrm{M}^{3}$ \\ ${ }^{1}$ Undergraduate student, ${ }^{2}$ Professor, ${ }^{3}$ Professor and Head, Department of Oral and Maxillofacial Pathology, Vishnu Dental College, \\ India
}

Correspondence: Swetha.p@vdc.edu.in

\begin{abstract}
Background: Reading has always been an important element since education has stepped into this world the ideology of printing of letters on papers got transformed into textbooks. Slowly in the mid-1970s, the age of digitalization got started which gave birth to E-books. But it is not only the technology that got restructured, society is also responsible regard these issues. In this study, many of the students were suddenly sent home because of the pandemic and they were in short of textbooks and they had to gear up with e-books for their exam preparation. Hence the study aimed to find out which had higher perception levels among e-book as well as a textbook.
\end{abstract}

Materials and methodology: A total of 100 bds students took part in this study those who have recently completed their first bds examinations. The questionnaire was composed of 10 questions compiling various segments related to e-books as well as textbooks. It was circulated to them via google forms. The questionnaire was a agree to disagree type whose options were ranging from strongly agree to strongly disagree.

Results: A total of 100 students had given their responses and the results show that $78 \%$ of the students preferred textbooks and remain $28 \%$ voted for e-books. This study was performed irrespective of cast sex and gender. It also showed that $75 \%$ of the student show memory apprehension more in textbooks rather than in e-books.

Conclusion: Most of the students in the study preferred textbooks rather than e-books but they also apprehend that textbook is not the only way to read. The students are focused on their best output.

Key words: E-books, text-books, perception levels, efficacy, dental students, students

\section{Introduction}

Textbooks have been a guide since education stepped into this world. Even if we turn our pages back to ancient times, we come across inscriptions made on leaves, rocks, sculptures, and many more, from there the ideology of writing started which led to printed books. In the mid-1970s ever since the age of digitization has started the evolution of textbooks took place which gave birth to e-books. [1,2]

E-learning has transformed into various forms such as tablets, ipad, and kindle which became a fastgrowing technology in no time. Considering various factors like cost, accessibility, maintenance, and eco-friendly there was a gradual decline in conventional reading which led to the downfall of many book stores that made them shut their doors and get exhausted [1]. But ultimately it is not only the devices or the technology that evolved, either society had too. So, in this lockdown, the students were abruptly sent home because of the pandemic which led to the shortage of textbooks that made them introduced to ee-textbooks vs Text books - Dental students perception reading for their preparation to get done. Taking this as an opportunity our present study is an attempt to find out which type of learning has better efficiency and intellectual than the other.

\section{Materials and Methodology:}

A questionnaire study was done on the 1st BDS students who have completed their university examinations irrespective of gender and age. All the study participants had volunteered and completed the questionnaire consisting of a set of 10 questions which was validated by the institutional ethics committee of Vishnu dental college with ref no IEVDC/2021/UGD1/OP/Q/65. The students other than 1st BDS were excluded from this study. This was an agree-disagree questionnaire whose options were ranging from strongly agree to strongly disagree. The questions were based on the various aspects related to both textbooks and e-book. Test-retest reliability was conducted and the Cronbach's alpha $(\alpha)$ value was found to be 0.83 . For every response, the options were ranging 
from strongly agree to strongly disagree. Data was collected via google forms and statistical analysis for knowledge, awareness was computed, and results obtained. Data management was performed by using a simple bar and pie charts with percentage (\%).

\section{Questionanaire:}

1. Textbook reading improvises your memory when compared to e-books

2. E-books reading causes shifting of focus when compared to textbooks (notifications, calls, messages)

3. Increased screen time in reading e-books may lead to adverse health effects (eye defects, headache, etc.)

4. E-reading helps in quick revision of the content

5. Preparation with e-books consumes more time

6. Content sharing is easier by e-books than textbooks

7. Textbooks are more economical than e-books (one device many books)

8. E-books have augmented reality experience when compared to textbooks (animated and graphic contents)

9. Textbooks are easier to available than e-books

10. What are your opinions/views about the choice of reading in the future?

\section{Results:}

1st BDS students who recently appeared for their university examinations were provided a validated questionnaire and their responses were assessed and displayed in a bar graph: (fig-1)

$75 \%$ of students say that they absorb more information when they read Text Books when compared to E-books. $78 \%$ of students infer that they get distracted while they use E-Books. $62 \%$ of students strongly agree that screen time may be health hazardous (headache and eye strain) when compared to Text Book reading. $75 \%$ of students agree that E-books help in quick revision than Text Books. Interestingly here the availability of either EBooks or Text Books was equally voted which indicates the advancement of digitization. $88 \%$ of the students prefer E-Books rather than Text Books as their content sharing is fast and easier.

\section{Discussion:}

Comparison of student preferences and use of ebooks had shown up many important findings. There were no age and gender factors involving in the study [3]. It was also interesting regarding the availability of the $\mathrm{E}$ and TEXT books which were equally voted that indicated a greater amount of digitization going around the world. Concerning the comments were given by the study participants, previous use of e-books doesn't increase the preference for it.[1] the students were in search of the means through which they could achieve their best output .

Concerning the health issues, there is also a massive increase in eye strain and headache cases these days. Speaking, in general most of the people exclusively the youngsters find these electronic gadgets as a medium to

$1^{\text {st }}$ BDS students who have recently completed their university examinations were included

1

A validated questionnaire was given to all the participants via Google forms.

Questionnaire reliability was found to be 0.83 (cronbachs alpha value)

1

Responses were recorded and assessed based on their mental attitudes. 


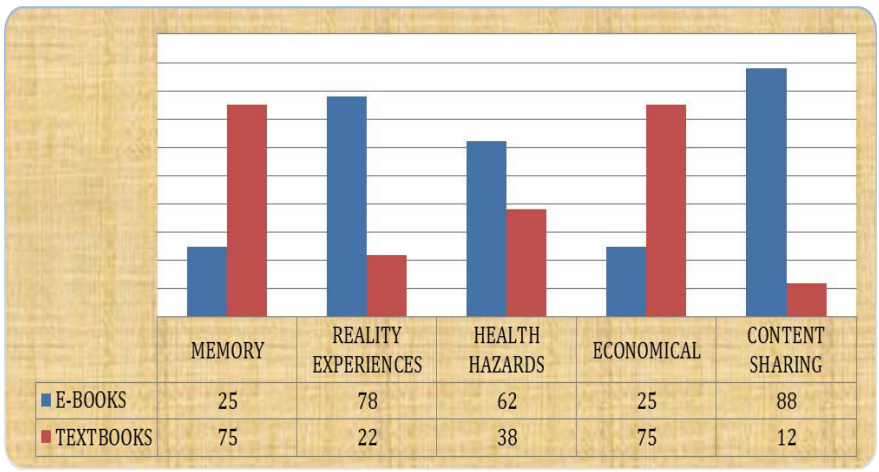

Fig-1

get away from their worries, depressions, etc. Regarding this subject, some studies also say that excessive screen time may destroy our eyes which may lead to further problems as age progresses.[4] The harmful rays or the blue light to be more specific are released from electronic gadgets are much harmful to our eyes and may also suppress the body's melatonin production which alters our sleep cycle. Psychologically speaking many of the people including the students complain that they are experiencing some kind of discomfort studying hours long in the electronic gadgets. Many syndromes such as ipad neck, computer vision syndrome, and screen-related sleeplessness are also some upcoming cases regarding these subjects.[4]

By grouping all the elements are given in the questionnaire it can find out that there was no actual difference between e-books and textbooks. Perhaps the reason for the low percentage is because of the different ways of adapting to either of the means according to their compatibility.

Apart from these, the advantages and disadvantages of either segment were also included in this study. Textbooks help to increase our memory, they get less distracted, and they're easy on the eyes,

No need for current and batteries and it's great for notes taking. But, on the other side of the coin they're a bit noneco-friendly, can't be carried everywhere and their maintenance is a tedious process.[4] E-books are like one device many books, they're easily accessible, they act as a quick guide, they're eco-friendly and maintained freely. On the other hand, they're distracting, health hazardous, can't be afforded by everyone, and require electricity and batteries.

\section{Conclusion}

In this fast-growing world, technology is drifting us towards its digitization but, it doesn't mean to leave our roots. It depends on a person's interest, ultimately the one who makes up the best choice will get the best output

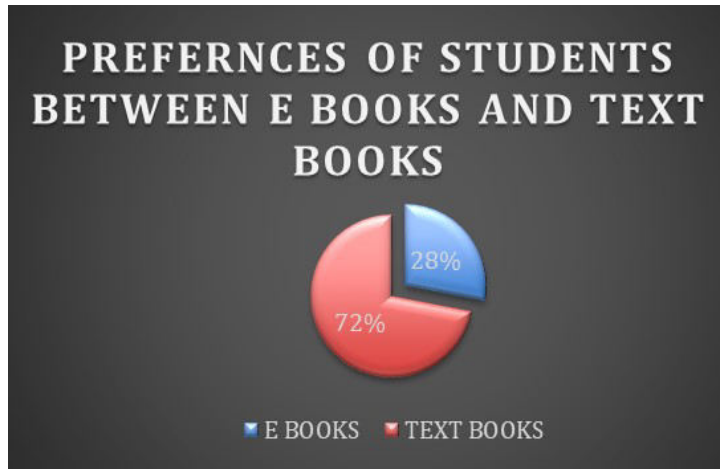

Fig-2

A person should always have caution in his mind whether the technology codes our mind or we code the technology. We should also give some concern by dividing the attention between a pixel and ink. Finally, when it comes to intense reading long pieces of plain text, paper and ink may still have the advantage. But the text is not the only way to read. So, in this study, many of the participants were abruptly sent home without prior notice because of the pandemic and lockdown. This led to the shortage of textbooks which made them adapted to elearning. Considering both the experiences $72 \%$ of the students voted for textbooks and $28 \%$ voted for e-books. (fig-2)

\section{References}

1. Geethika B, Karpagam K. Comparing the choice of Ebooks Vs Textbooks among dental students-A Questionnaire-based study. Research Journal of Pharmacy and Technology. 2016 Aug 1;9(8):1077.

2. Zhang Y, Kudva S. E-books versus print books: Readers' choices and preferences across contexts. Journal of the Association for Information Science and Technology. 2014 Aug;65(8):1695-706.

3. Woody WD, Daniel DB, Baker CA. E-books or textbooks: Students prefer textbooks. Computers \& education. 2010 Nov 1;55(3):945-8.

4. Myrberg C, Wiberg N. Screen vs. paper: what is the difference for reading and learning?. Insights. 2015 Jul 7;28(2).

5. Jabr F. The reading brain in the digital age: The science of paper versus screens. Scientific American. 2013 Apr 11;11(5). 